\title{
Non-invasive measurement of pulse pressure variation using a finger- cuff method in obese patients having laparoscopic bariatric surgery
}

\author{
Moritz Flick $^{1} \cdot$ Roman Schumann $^{2} \cdot$ Phillip Hoppe $^{1} \cdot$ Iwona Bonney $^{2} \cdot$ Wilbert Wesselink $^{3} \cdot$ Bernd Saugel $^{1,4} \oplus$
}

Received: 30 June 2020 / Accepted: 25 October 2020 / Published online: 10 November 2020

(c) The Author(s) 2020

\begin{abstract}
Pulse pressure variation (PPV) is a dynamic cardiac preload variable used to predict fluid responsiveness. PPV can be measured non-invasively using innovative finger-cuff systems allowing for continuous arterial pressure waveform recording, e.g., the Nexfin system [BMEYE B.V., Amsterdam, The Netherlands; now Clearsight (Edwards Lifesciences, Irvine, $\mathrm{CA}, \mathrm{USA})]\left(\mathrm{PPV}_{\text {Finger }}\right)$. However, the agreement between $\mathrm{PPV}_{\text {Finger }}$ and PPV derived from an arterial catheter $\left(\mathrm{PPV}_{\mathrm{ART}}\right)$ in obese patients having laparoscopic bariatric surgery is unknown. We compared $P P V_{\text {Finger }}$ and $P P V_{A R T}$ at 6 time points in 60 obese patients having laparoscopic bariatric surgery in a secondary analysis of a prospective method comparison study. We used Bland-Altman analysis to assess absolute agreement between $\mathrm{PPV}_{\mathrm{Finger}}$ and $\mathrm{PPV}_{\mathrm{ART}}$. The predictive agreement for fluid responsiveness between $\mathrm{PPV}_{\text {Finger }}$ and PPV $\mathrm{ART}_{\text {was }}$ waluated across three PPV categories (PPV < 9\%, PPV 9-13\%, PPV $>13 \%$ ) as concordance rate of paired measurements and Cohen's kappa. The overall mean of the differences between $\mathrm{PPV}_{\text {Finger }}$ and PPV Cohen's kappa of 0.53 . The mean of the differences was $-0.7 \pm 3.8 \%$ (95\%-LoA -8.1 to $6.7 \%$ ) without pneumoperitoneum in horizontal position and $1.1 \pm 4.8 \%(95 \%$ - LoA -8.4 to $10.5 \%)$ during pneumoperitoneum in reverse-Trendelenburg position. The absolute agreement and predictive agreement between $\mathrm{PPV}_{\text {Finger }}$ and $\mathrm{PPV}_{\mathrm{ART}}$ are moderate in obese patients having laparoscopic bariatric surgery.
\end{abstract}

Keywords Fluid responsiveness $\cdot$ Dynamic preload variable $\cdot$ Clearsight $\cdot$ Nexfin $\cdot$ Hemodynamic monitoring

\section{Introduction}

Moritz Flick and Roman Schumann contributed equally to the work.

Electronic supplementary material The online version of this article (https://doi.org/10.1007/s10877-020-00614-8) contains supplementary material, which is available to authorized users.

Bernd Saugel

bernd.saugel@gmx.de

1 Department of Anesthesiology, Center of Anesthesiology and Intensive Care Medicine, University Medical Center Hamburg-Eppendorf, Martinistrasse 52, 20246 Hamburg, Germany

2 Department of Anesthesiology and Perioperative Medicine, Tufts University School of Medicine, Boston, MA, USA

3 Edwards Lifesciences, Irvine, CA, USA

4 Outcomes Research Consortium, Cleveland, OH, USA
Pulse pressure variation (PPV) is a dynamic cardiac preload variable used to predict fluid responsiveness [1-3]. PPV results from intermittent changes in venous return and cardiac preload during mechanical ventilation $[1,2]$. PPV reliably predicts fluid responsiveness in patients with sinus rhythm and controlled mechanical ventilation with a tidal volume of at least $8 \mathrm{~mL} / \mathrm{kg}$ predicted body weight [4]. PPV is calculated based on the arterial pressure (AP) waveform recorded over several respiratory cycles, usually using an arterial catheter [5].

PPV may also be measured non-invasively using innovative finger-cuff systems allowing for continuous AP waveform recording [6, 7], e.g., with the Nexfin system [BMEYE B.V., Amsterdam, The Netherlands; now Clearsight (Edwards Lifesciences, Irvine, CA, USA)]. Nexfin-derived $\mathrm{AP}$ and PPV ( $\left.\mathrm{PPV}_{\text {Finger }}\right)$ have been tested and validated in patients having cardiothoracic [8-10] and major abdominal [11] surgery. Nexfin-derived AP measurements also showed 
good absolute and trending agreement with invasive AP measurements in obese patients having laparoscopic bariatric surgery [12]. However, the agreement between $\mathrm{PPV}_{\text {Finger }}$ and PPV derived from an arterial catheter $\left(\mathrm{PPV}_{\mathrm{ART}}\right)$ in obese patients having laparoscopic bariatric surgery is unknown.

Therefore, we sought to investigate the absolute and predictive agreement between $P_{P V}$ Finger and $P P V_{A R T}$ in obese patients having laparoscopic bariatric surgery. As a secondary endpoint we examined pneumoperitoneum- and reverse Trendelenburg position-induced changes in $\mathrm{PPV}_{\mathrm{ART}}$.

\section{Methods}

\subsection{Study design and patients}

This study is a secondary analysis of a prospective method comparison study that investigated continuous non-invasive finger-cuff AP measurements and continuous invasive AP measurements in bariatric surgical patients. The primary prospective study was approved by the Ethics Committee (No. 9743) and patients provided written informed consent. The results from the primary study will be reported separately. In this secondary analysis, we compared $\mathrm{PPV}_{\text {Finger }}$ and PPV $_{\text {ART }}$. This secondary analysis was independently approved by the Tufts Health Sciences Institutional Review Board (No. 11704).

The primary study included adults scheduled for elective laparoscopic bariatric surgery (gastric bypass, sleeve gastrectomy, and gastric banding) with a body mass index (BMI) $\geq 40 \mathrm{~kg} / \mathrm{m}^{2}$ and American Society of Anesthesiologists physical status classification of $<$ IV. Patients with upper or lower extremity edema, history of ipsilateral axillary or inguinal lymph node dissection, vascular or anatomical abnormalities, carpal tunnel syndrome, negative modified Allen's test, absence of a palpable ipsilateral ulnar pulse, and atrial fibrillation were excluded. For this secondary analysis, we only included patients with recorded $P V_{\text {Finger }}$ and $\mathrm{PPV}_{\mathrm{ART}}$ measurements.

\subsection{Anesthesia management}

General anesthesia was induced with fentanyl, propofol, lidocaine, and rocuronium or succinylcholine. Either sevoflurane or desflurane in combination with fentanyl and hydromorphone were administered for maintenance of general anesthesia. Patients were positioned horizontally during surgical preparation of the abdomen and skin closure. Pneumoperitoneum was established with a target pressure of $15 \mathrm{mmHg}$. During the laparoscopic surgical procedure all patients were positioned in a reverse-Trendelenburg position. Both arms were positioned and secured on padded arm boards.

\subsection{Study measurements}

We recorded the AP waveform non-invasively using the Nexfin system with the finger-cuffs placed on the middle phalanx of the middle or ring finger ipsilateral to the radial arterial catheter. The heart reference system was leveled to the right atrium of the patient according to the manufacturer's specifications. The Nexfin system automatically calculates PPV $_{\text {Finger }}$ based on proprietary pulse wave analysis of the non-invasively recorded AP waveform. $P P V_{\text {Finger }}$ is calculated every $5 \mathrm{~s}$ using a $15 \mathrm{~s}$ episode

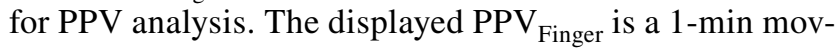
ing average. $P P V_{\text {Finger }}$ was the test method.

Simultaneously, we recorded the AP waveform invasively using a 20 gauge radial arterial catheter. The arterial catheter was leveled and zeroed to the right atrium of the patient using a disposable transducer [13]. The AP waveform was tested for its damping properties with a fast-flush test to ensure a high-quality AP signal. PPV was automatically calculated using the algorithm of the Philips Intellivue MP 90 patient monitor (Philips Healthcare, Andover, MA, USA), which averages four consecutive $8 \mathrm{~s}$ PPV measurements [14-16]. PPV $\mathrm{ART}_{\text {was }}$ the reference method.

We recorded $P P V_{\text {Finger }}$ and $\mathrm{PPV}_{\mathrm{ART}}$ at 6 predefined time points (T1: within 15 min prior to abdominal insufflation; T2: 3 min after pneumoperitoneum insufflation; T3: 15 min after pneumoperitoneum insufflation; T4: $30 \mathrm{~min}$ after pneumoperitoneum insufflation; T5: 45 min after pneumoperitoneum insufflation; T6: 3 min after pneumoperitoneum desufflation). Measurements at T1 and T6 were performed in horizontal position and measurements at $\mathrm{T} 2-5$ were performed in $30^{\circ}$ reverse-Trendelenburg position. We visually inspected the AP waveform just before each study measurement to exclude AP waveform artifacts or abnormalities.

\subsection{Statistical analysis}

Descriptive data are shown as median (range) for continuous data and as absolute frequencies and percentages for categorical data. The mean \pm standard deviation (SD) was calculated for $\mathrm{PPV}_{\text {Finger }}$ and $\mathrm{PPV}_{\mathrm{ART}}$; additionally, we calculated the mean $\pm \mathrm{SD}$ for $\mathrm{PPV}_{\text {Finger }}$ and $\mathrm{PPV}_{\mathrm{ART}}$ separately for episodes with and without pneumoperitoneum. The absolute agreement between PPV $_{\text {Finger }}$ and PPV $\mathrm{PRT}_{\mathrm{ART}}$ was investigated using Bland-Altman analysis accounting for repeated measurements within individuals $[17,18]$. The mean of the differences, the SD of the mean of the differences, and the 95\% limits of agreement (95\%-LoA; i.e., mean of the differences $\pm 1.96 \mathrm{SD}$ of the mean of the differences) are reported to describe the trueness and precision of agreement $[19,20]$. 
The predictive agreement between $P P V_{\text {Finger }}$ and $\mathrm{PPV}_{\mathrm{ART}}$ for fluid responsiveness was evaluated across previously defined categories reflecting clinical practice using the "gray-zone" approach (PPV < 9\%, PPV 9-13\%, PPV $>13 \%$ ) [21, 22]. We separately evaluated the predictive agreement during pneumoperitoneum with adapted PPV categories (PPV < 7\%, PPV 7-20\%, PPV > 20\%) [23]. The concordance rate of paired measurements, defined as the number of concordantly paired measurements divided by the total number of paired measurements, and Cohen's kappa were calculated to evaluate predictive agreement. We defined a Cohen's kappa value of $<0$ as no agreement, $0-0.20$ as slight, $0.21-0.40$ as fair, $0.41-0.60$ as moderate, $0.61-0.80$ as substantial, and $0.81-1.00$ as near perfect agreement [24].

To illustrate the impact of pneumoperitoneum and reverse-Trendelenburg positioning on $\mathrm{PPV}_{\mathrm{ART}}$, we created box plots of all PPV measurements, PPV measurements without pneumoperitoneum, and PPV measurements during pneumoperitoneum. We compared consecutive $\mathrm{PPV}_{\mathrm{ART}}$ measurements before and after pneumoperitoneum insufflation (T1 vs. T2) and before and after pneumoperitoneum desufflation (T5 vs. T6) using Wilcoxon rank sum test. A p-value less than 0.05 was considered statistically significant.

For statistical analysis, we used Excel (Microsoft, Redmond, Washington, USA), and MedCalc (Version 19.2.0, MedCalc Software Ltd., Ostend, Belgium).

\section{Results}

We analyzed a total of 337 paired $\mathrm{PPV}_{\text {Finger }}$ and $\mathrm{PPV}$ ART measurements from 60 patients with sinus rhythm. Patient characteristics and procedural data are presented in Table 1. 108 Paired $\mathrm{PPV}_{\text {Finger }}$ and $\mathrm{PPV}_{\mathrm{ART}}$ measurements were obtained without pneumoperitoneum in horizontal position, and 229 during pneumoperitoneum in reverse-Trendelenburg position (Fig. 1; Table S1).

The overall mean of the differences between $\mathrm{PPV}_{\text {Finger }}$ and $\mathrm{PPV}_{\mathrm{ART}}$ was $0.5 \pm 4.6 \%$ (95\%-LoA: -8.6 to $9.6 \%$; Fig. 2a). For measurements without pneumoperitoneum and in horizontal position, the mean of the differences between $\mathrm{PPV}_{\text {Finger }}$ and $\mathrm{PPV}_{\mathrm{ART}}$ was $-0.7 \pm 3.8 \%(95 \%$-LoA: -8.1 to $6.7 \%$; Fig. 2b). During pneumoperitoneum and reverseTrendelenburg position, the mean of the differences between $\mathrm{PPV}_{\text {Finger }}$ and $\mathrm{PPV}_{\mathrm{ART}}$ was $1.1 \pm 4.8 \%$ (95\%-LoA: -8.4 to 10.5\%; Fig. 2c).

The overall predictive agreement between $\mathrm{PPV}_{\text {Finger }}$ and $\mathrm{PPV}_{\mathrm{ART}}$ across the predefined categories for fluid responsiveness was $72.4 \%$ with a Cohen's kappa of 0.53 (Table 2). The predictive agreement between $\mathrm{PPV}_{\text {Finger }}$ and $\mathrm{PPV} \mathrm{V}_{\mathrm{ART}}$ without and during pneumoperitoneum is shown in Supplementary Tables S2 and S3.

Mean $\pm \mathrm{SD} \mathrm{PPV}_{\mathrm{ART}}$ increased from $12.4 \pm 5.4 \%$ before (T1) to $18.8 \pm 6.7 \%(\mathrm{p}<0.0001)$ after $(\mathrm{T} 2)$ pneumoperitoneum insufflation and reverse-Trendelenburg positioning. Pneumoperitoneum desufflation and re-positioning
Fig. 1 Box plots showing pulse pressure variation (PPV) (\%) from the non-invasive finger cuff system Nexfin ( $\mathrm{PPV}_{\text {Finger }}$ ) and the invasive arterial catheter $\left(\mathrm{PPV}_{\mathrm{ART}}\right)$. PPV values are shown as box plots separately for all measurements, measurements without pneumoperitoneum in horizontal position, and measurements during pneumoperitoneum in reverse-Trendelenburg position

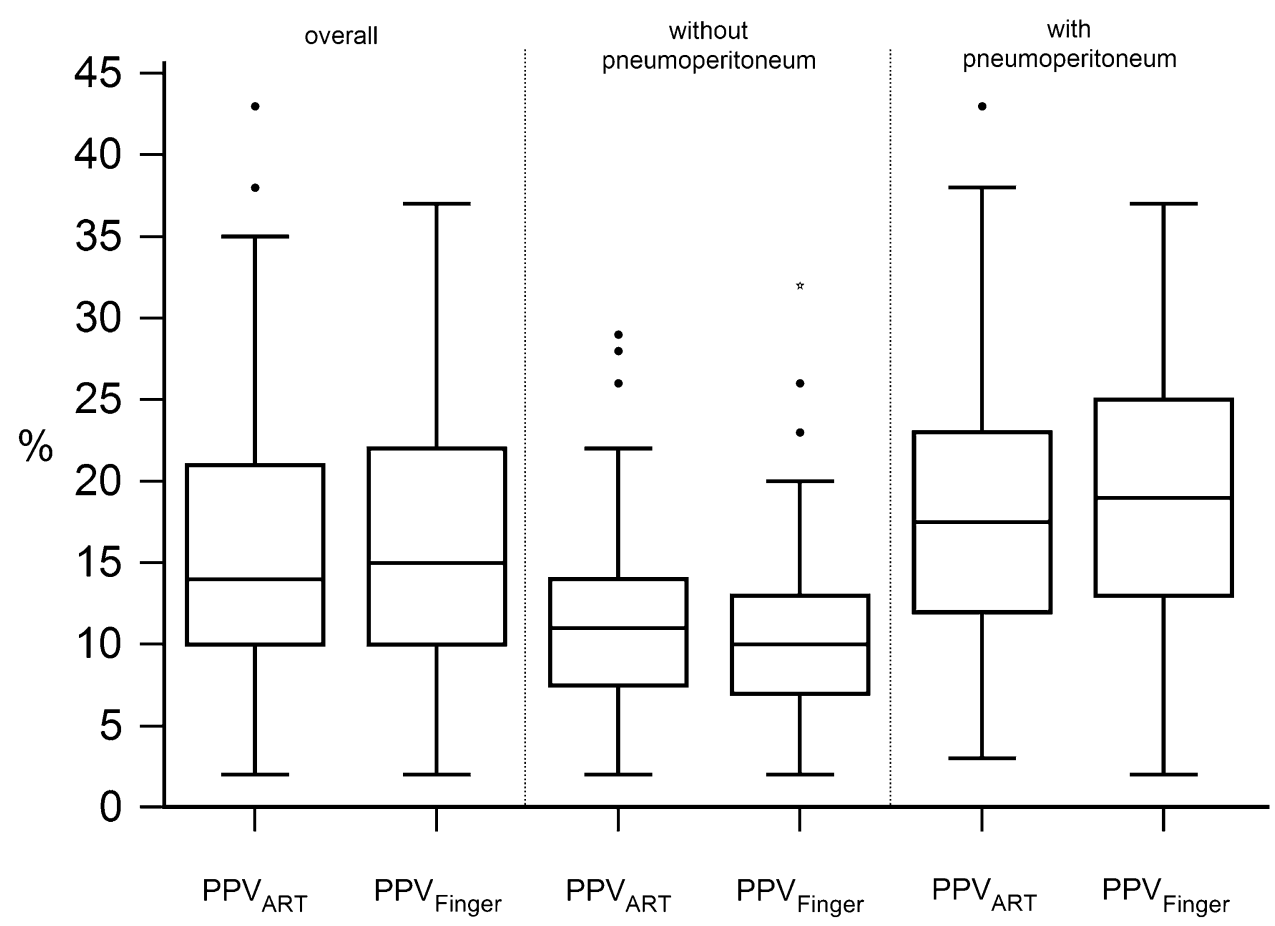


Table 1 Patient characteristics

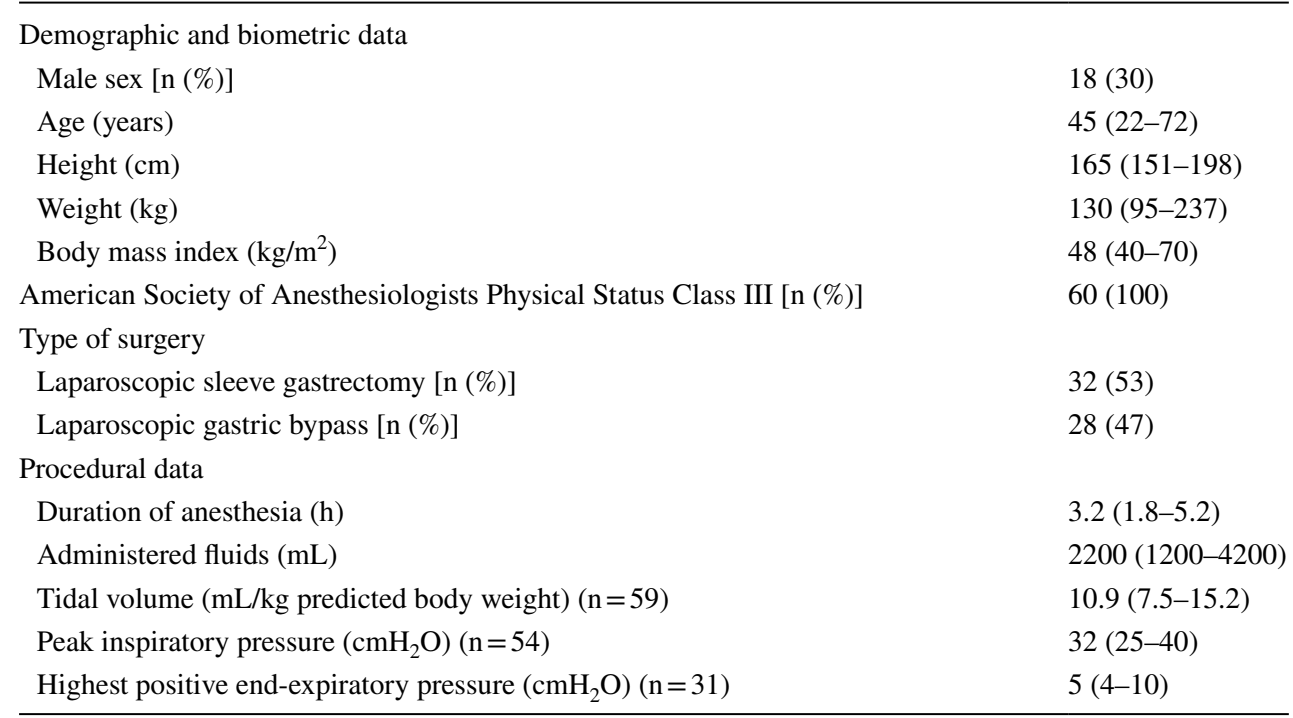

Data are shown as median (range) or absolute (relative frequencies)

in horizontal position decreased mean $\mathrm{PPV}_{\mathrm{ART}}$ from $18.3 \pm 7.7 \%$ (T5) to $10.7 \pm 4.6 \%$ (T6) $(\mathrm{p}<0.0001)$ (Fig. 3$)$.

\section{Discussion}

We investigated the absolute and predictive agreement

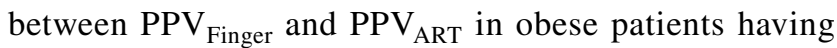
laparoscopic bariatric surgery. The absolute agreement, i.e. the trueness and precision of agreement [19, 20], and the predictive agreement across three predefined PPV categories between PPV Finger $_{\text {and PPV }}$ ART were moderate. Pneumoperitoneum insufflation and reverse-Trendelenburg positioning transiently increased PPV $\mathrm{ART}_{\text {. }}$

Finger-cuff technologies are an alternative to arterial catheters for continuous AP monitoring in morbidly obese patients having surgery $[12,25]$. In addition to continuous AP monitoring, finger-cuff technologies allow for calculation of advanced hemodynamic variables including PPV. PPV predicts fluid responsiveness in patients receiving controlled mechanical ventilation and is therefore part of many perioperative goal-directed therapy protocols [4, 26, 27].

In our study, the absolute agreement between $\mathrm{PPV}_{\text {Finger }}$ and PPV $\mathrm{ART}_{\mathrm{AR}}$ was moderate, but worse than in previous stud-

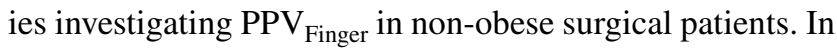
one of the first studies, the mean of the differences between PPV $_{\text {Finger }}$ and PPV ART $_{\text {was }}-1.0 \%$ (95\%-LoA: -4.3 to $2.4 \%$ ) in 19 patients after coronary artery bypass graft surgery [10]. Similar results were reported in 19 patients after major abdominal surgery with a mean of the differences of $1.5 \%$ (95\%-LoA: -2.7 to $5.7 \%$ ) [11]. In contrast to these previous studies, we investigated morbidly obese patients having laparoscopic bariatric surgery. Pneumoperitoneum during laparoscopic surgery increases intraabdominal pressure-that is often already elevated at baseline in obese patients - and may thus reduce vascular compliance and venous return resulting in high PPV [28, 29]. Higher overall PPV values in our study may — in part-explain wider 95\%-LoA between PPV Finger $_{\text {and }}$ PPV $_{\mathrm{ART}}$ in the present study compared to previous studies $[10,11]$. Additionally, these studies used offline calculation with the same formula for both, PPV Finger and PPV $\mathrm{ART}_{\mathrm{A} T}[10,11]$, whereas we compared $P P V_{\text {Finger }}$ automatically calculated using the $P P V_{\text {Finger }}$ algorithm and $\mathrm{PPV}_{\mathrm{ART}}$ calculated by the patient monitor.

We also investigated the predictive agreement between PPV $\mathrm{Finger}_{\text {and }}$ PPV $\mathrm{ART}_{\mathrm{AR}}$ across predefined PPV categories to investigate the ability of $\mathrm{PPV}_{\text {Finger }}$ to guide fluid therapy. Overall, the predictive agreement was moderate according to Cohen's kappa for both conventional PPV categories [21] and PPV categories considering pneumoperitoneum [23]. Further studies using fluid challenges to test whether PPV $V_{\text {Finger }}$ is able to actually predict fluid responsiveness during laparoscopic bariatric surgery in obese patients are needed.

Pneumoperitoneum insufflation increased PPV in our study, which is in agreement with results from experimental studies [30-32] and a study in non-obese patients [33]. Furthermore, positioning patients in reverse-Trendelenburg may have additionally increased PPV because of a further decrease in venous return [34]. The agreement between

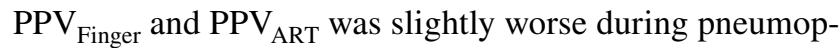
eritoneum and reverse-Trendelenburg positioning compared to without pneumoperitoneum and the horizontal position. However, pneumoperitoneum and reverse-Trendelenburg 

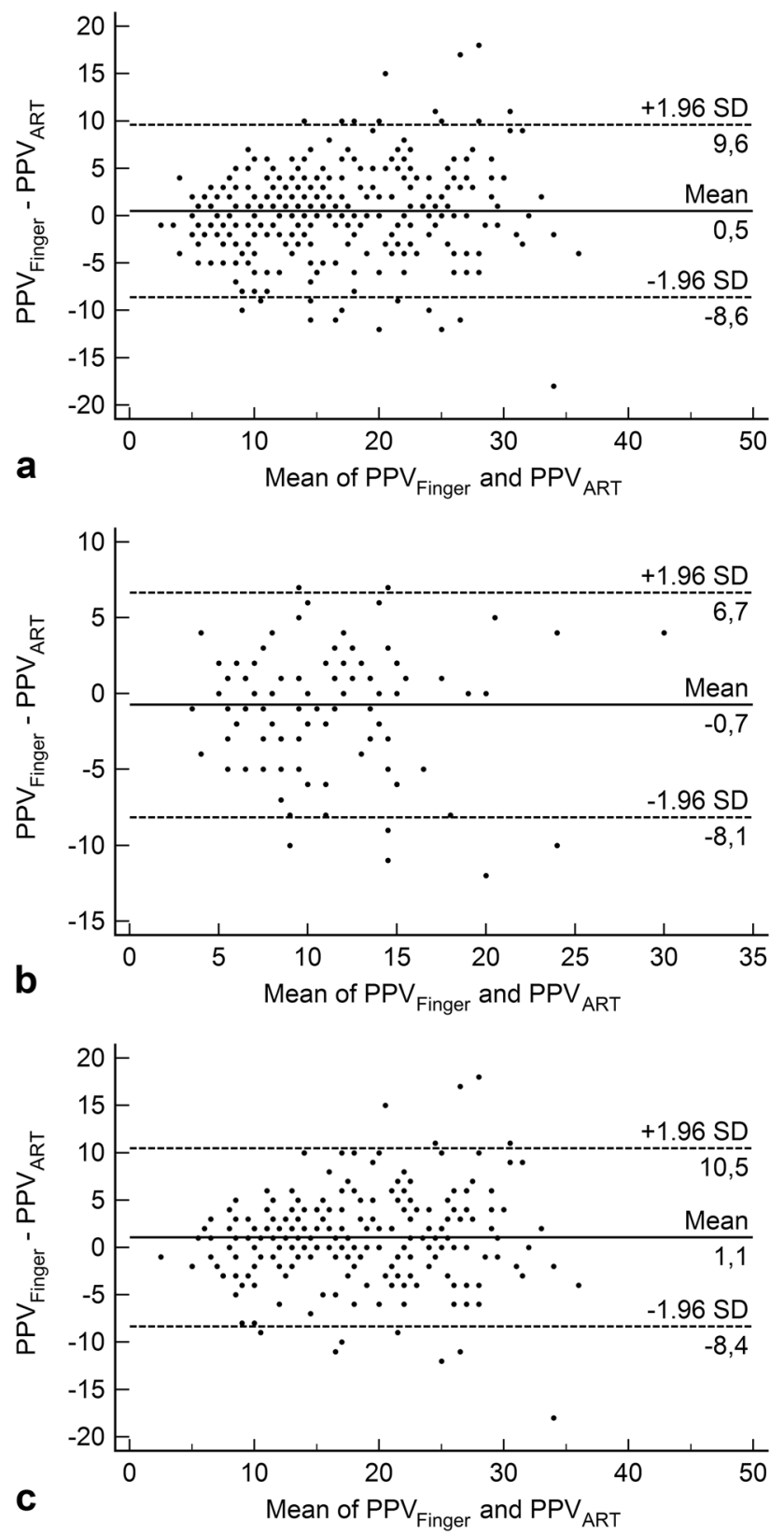

Fig. 2 Bland-Altman plots comparing pulse pressure variation (\%) from the non-invasive finger cuff system Nexfin ( $\left.P P V_{\text {Finger }}\right)$ and the invasive arterial catheter $\left(\mathrm{PPV}_{\mathrm{ART}}\right)$ for all measurements $(\mathbf{a})$, measurements without pneumoperitoneum in horizontal position (b), and measurements during pneumoperitoneum in reverse-Trendelenburg position (c)
Table 2 Distribution and predictive agreement of pulse pressure variation measurements across the three predefined categories

\begin{tabular}{lllll}
\hline PPV & \multicolumn{3}{l}{$\mathrm{PPV}_{\text {Finger }}$} \\
\cline { 2 - 4 } & $<9 \%$ & $9-13 \%$ & $>13 \%$ & \\
\hline$<9 \%$ & 38 & 12 & 1 & \\
$9-13 \%$ & 22 & 47 & 33 & Accordance rate $: 72.4 \%$ \\
$>13 \%$ & 5 & 20 & 159 & Cohen's kappa : 0.53 \\
\hline$P P V_{\text {Finger }}$ & pulse pressure variation measured with Nexfin, \\
$P P V_{\text {ART }}$ pulse pressure variation measured with the invasive arterial \\
catheter
\end{tabular}

positioning had little effect on the predictive agreement between PPV $\mathrm{Finger}_{\text {and }}$ PPV $\mathrm{ART}_{\mathrm{ART}}$, which was moderate under both conditions.

Based on our data, the assessment of fluid responsiveness using non-invasive PPV $\mathrm{F}_{\text {Finger }}$ during bariatric surgery should be interpreted cautiously. However, PPV Finger $_{\text {may }}$ add an additional measurement contributing to a decision for fluid administration, when additional physiological variables are available.

$\mathrm{PPV}_{\mathrm{ART}}$ was calculated automatically by the patient monitor. The gold standard for PPV measurement is post hoc manual calculation based on the invasively recorded AP waveform [5]. However, post hoc manual PPV calculation is impractical during routine clinical care. We did not perform any intervention, e.g. fluid challenge, and could thus not evaluate the utility of the Nexfin system to respond to actual fluid administration.

\section{Conclusions}

The absolute agreement and predictive agreement between

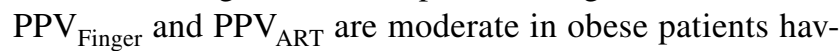
ing laparoscopic bariatric surgery. Pneumoperitoneum and reverse-Trendelenburg positioning transiently increase $\mathrm{PPV}_{\mathrm{ART}}$. 
Fig. 3 Spaghetti plots illustrating arterial catheter-derived pulse pressure variation $\left(\mathrm{PPV}_{\mathrm{ART}}\right)(\%)$ before (T1) and after (T2) pneumoperitoneum insufflation and reverse-Trendelenburg positioning $(\mathbf{a} ; \mathrm{n}=48)$ as well as before (T5) and after (T6) pneumoperitoneum desufflation and re-positioning in horizontal position $(\mathbf{b} ; \mathrm{n}=56)$ (both $\mathrm{p}<0.0001$ )
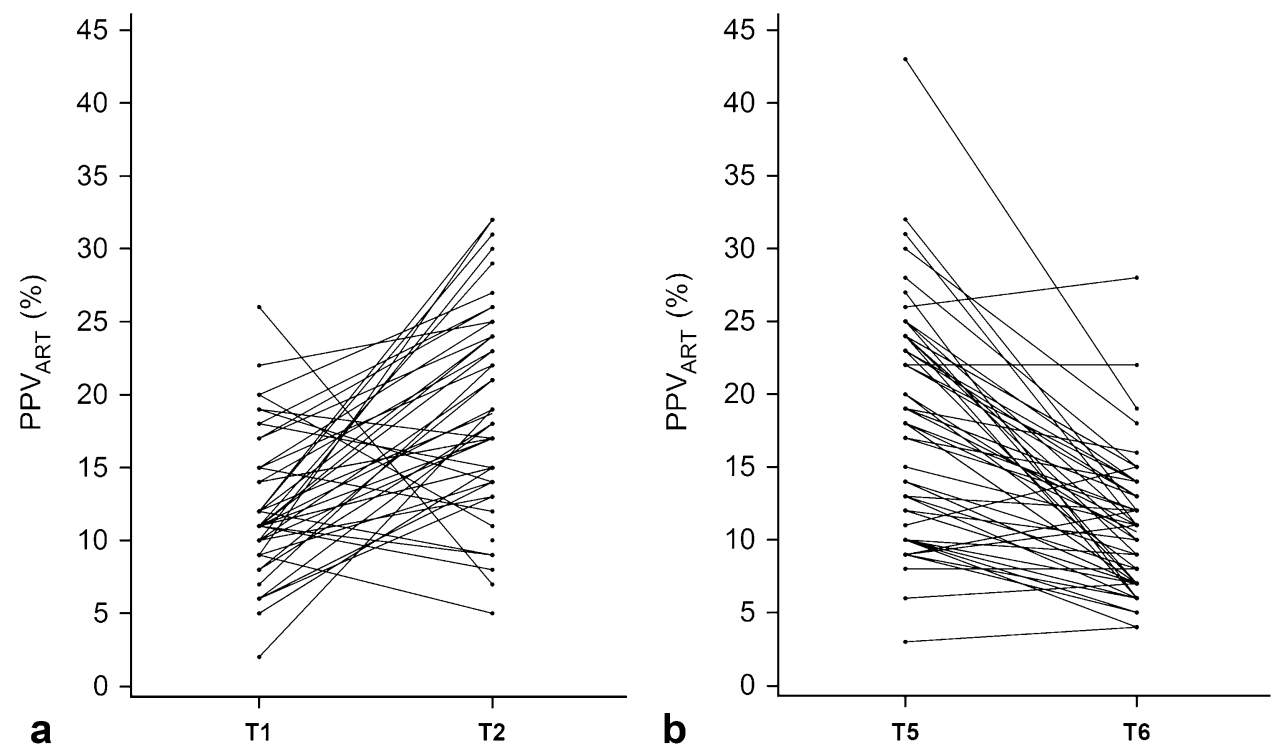

Acknowledgements The authors wish to acknowledge Omar Alyamani, MBBS, and Ingrid Moreno-Duarte, M.D., for early protocol concepts and preliminary statistical analysis respectively.

Funding Open Access funding enabled and organized by Projekt DEAL. BMEYE B.V. (Amsterdam, The Netherlands): now Edwards Lifesciences (Irvine, CA, USA)—-provided the technical equipment for the study.

\section{Compliance with Ethical Standards}

Conflict of interest MF received honoraria for consulting from $\mathrm{CN}$ Systems Medizintechnik GmbH (Graz, Austria). RS received royalties as author and reviewer for obesity and sleep medicine related chapters in Up-To-Date (Wolters Kluwer; Waltham, MA, USA). PH has no conflicts of interest to declare. IB has no conflicts of interest to declare. WW is an employee of Edwards Lifesciences (Irvine, CA, USA). BS received honoraria for consulting, honoraria for giving lectures, and refunds of travel expenses from Edwards Lifesciences (Irvine, CA, USA). BS received honoraria for consulting, institutional restricted research grants, honoraria for giving lectures, and refunds of travel expenses from Pulsion Medical Systems SE (Feldkirchen, Germany). BS received institutional restricted research grants, honoraria for giving lectures, and refunds of travel expenses from CNSystems Medizintechnik GmbH (Graz, Austria). BS received institutional restricted research grants from Retia Medical LLC. (Valhalla, NY, USA). BS received honoraria for giving lectures from Philips Medizin Systeme Böblingen GmbH (Böblingen, Germany). BS received honoraria for consulting, institutional restricted research grants, and refunds of travel expenses from Tensys Medical, Inc. (San Diego, CA, USA).

Ethical approval The primary prospective study was approved by the Tufts Health Sciences Institutional Review Board (No. 9743) and patients provided written informed consent. This secondary analysis was independently approved by the Tufts Health Sciences Institutional Review Board (No. 11704).

Informed consent The need for informed consent for this secondary analysis was waived.
Open Access This article is licensed under a Creative Commons Attribution 4.0 International License, which permits use, sharing, adaptation, distribution and reproduction in any medium or format, as long as you give appropriate credit to the original author(s) and the source, provide a link to the Creative Commons licence, and indicate if changes were made. The images or other third party material in this article are included in the article's Creative Commons licence, unless indicated otherwise in a credit line to the material. If material is not included in the article's Creative Commons licence and your intended use is not permitted by statutory regulation or exceeds the permitted use, you will need to obtain permission directly from the copyright holder. To view a copy of this licence, visit http://creativecommons.org/licenses/by/4.0/.

\section{References}

1. Monnet X, Marik PE, Teboul JL. Prediction of fluid responsiveness: an update. Ann Intensive Care. 2016;6(1):111. https://doi. org/10.1186/s13613-016-0216-7.

2. Teboul JL, Monnet X, Chemla D, Michard F. Arterial pulse pressure variation with mechanical ventilation. Am J Respir Crit Care Med. 2019;199(1):22-31. https://doi.org/10.1164/rccm.201801-0088CI.

3. Perel A. Using dynamic variables to guide perioperative fluid management. Anesthesiology. 2020;133(4):929-935. https://doi. org/10.1097/ALN.0000000000003408

4. Yang X, Du B. Does pulse pressure variation predict fluid responsiveness in critically ill patients? A systematic review and metaanalysis. Crit Care. 2014;18(6):650. https://doi.org/10.1186/s1305 4-014-0650-6.

5. Michard F, Boussat S, Chemla D, Anguel N, Mercat A, Lecarpentier Y, Richard C, Pinsky MR, Teboul JL. Relation between respiratory changes in arterial pulse pressure and fluid responsiveness in septic patients with acute circulatory failure. Am J Respir Crit Care Med. 2000;162(1):134-8. https://doi.org/10.1164/ajrcc m.162.1.9903035.

6. Meidert AS, Saugel B. Techniques for non-invasive monitoring of arterial blood pressure. Front Med (Lausanne). 2017;4:231. https ://doi.org/10.3389/fmed.2017.00231.

7. Saugel B, Dueck R, Wagner JY. Measurement of blood pressure. Best Pract Res Clin Anaesthesiol. 2014;28(4):309-22. https://doi. org/10.1016/j.bpa.2014.08.001. 
8. Fischer MO, Avram R, Carjaliu I, Massetti M, Gerard JL, Hanouz JL, Fellahi JL. Non-invasive continuous arterial pressure and cardiac index monitoring with Nexfin after cardiac surgery. Br J Anaesth. 2012;109(4):514-21. https://doi.org/10.1093/bja/aes215.

9. Martina JR, Westerhof BE, van Goudoever J, de Beaumont EM, Truijen J, Kim YS, Immink RV, Jobsis DA, Hollmann MW, Lahpor JR, de Mol BA, van Lieshout JJ. Noninvasive continuous arterial blood pressure monitoring with Nexfin(R). Anesthesiology. 2012;116(5):1092-103. https://doi.org/10.1097/ ALN.0b013e31824f94ed.

10. Lansdorp B, Ouweneel D, de Keijzer A, van der Hoeven JG, Lemson J, Pickkers P. Non-invasive measurement of pulse pressure variation and systolic pressure variation using a finger cuff corresponds with intra-arterial measurement. Br J Anaesth. 2011;107(4):540-5. https://doi.org/10.1093/bja/aer187.

11. de Wilde RB, de Wit F, Geerts BF, van Vliet AL, Aarts LP, Vuyk J, Jansen JR. Non-invasive continuous arterial pressure and pulse pressure variation measured with $\operatorname{Nexfin}((\mathrm{R}))$ in patients following major upper abdominal surgery: a comparative study. Anaesthesia. 2016;71(7):788-97. https://doi. org/10.1111/anae.13503.

12. Rogge DE, Nicklas JY, Schon G, Grothe O, Haas SA, Reuter DA, Saugel B. Continuous noninvasive arterial pressure monitoring in obese patients during bariatric surgery: an evaluation of the vascular unloading technique (Clearsight system). Anesth Analg. 2019;128(3):477-83. https://doi.org/10.1213/ANE.0000000000003943.

13. Saugel B, Kouz K, Meidert AS, Schulte-Uentrop L, Romagnoli S. How to measure blood pressure using an arterial catheter: a systematic 5-step approach. Crit Care. 2020;24(1):172. https:// doi.org/10.1186/s13054-020-02859-w.

14. Aboy M, McNames J, Thong T, Phillips CR, Ellenby MS, Goldstein B. A novel algorithm to estimate the pulse pressure variation index deltaPP. IEEE Trans Biomed Eng. 2004;51(12):2198-203. https://doi.org/10.1109/TBME.2004.834295.

15. Derichard A, Robin E, Tavernier B, Costecalde M, Fleyfel M, Onimus J, Lebuffe G, Chambon JP, Vallet B. Automated pulse pressure and stroke volume variations from radial artery: evaluation during major abdominal surgery. Br J Anaesth. 2009;103(5):67884. https://doi.org/10.1093/bja/aep267.

16. Cannesson M, Slieker J, Desebbe O, Bauer C, Chiari P, Henaine R, Lehot JJ. The ability of a novel algorithm for automatic estimation of the respiratory variations in arterial pulse pressure to monitor fluid responsiveness in the operating room. Anesth Analg. 2008;106(4):1195-200. https://doi.org/10.1213/01.ane.00002 97291.01615.5c (Table of contents).

17. Altman DG, Bland JM. Statistics notes: variables and parameters. BMJ. 1999;318(7199):1667. https://doi.org/10.1136/bmj.318.7199.1667.

18. Bland JM, Altman DG. Agreement between methods of measurement with multiple observations per individual. J Biopharm Stat. 2007;17(4):571-82. https://doi.org/10.1080/10543400701329422.

19. Squara P, Scheeren TWL, Aya HD, Bakker J, Cecconi M, Einav S, Malbrain M, Monnet X, Reuter DA, van der Horst ICC, Saugel B. Metrology Part 1: definition of quality criteria. J Clin Monit Comput. 2020. https://doi.org/10.1007/s10877-020-00494-y (Epub ahead of print).

20. Squara P, Scheeren TWL, Aya HD, Bakker J, Cecconi M, Einav S, Malbrain M, Monnet X, Reuter DA, van der Horst ICC, Saugel B. Metrology Part 2: procedures for the validation of major measurement quality criteria and measuring instrument properties. J Clin Monit Comput. 2020. https://doi.org/10.1007/s10877-020-00495 -x (Epub ahead of print).

21. Cannesson M, Le Manach Y, Hofer CK, Goarin JP, Lehot JJ, Vallet B, Tavernier B. Assessing the diagnostic accuracy of pulse pressure variations for the prediction of fluid responsiveness: a "gray zone" approach. Anesthesiology. 2011;115(2):231-41. https ://doi.org/10.1097/ALN.0b013e318225b80a.
22. Joosten A, Jacobs A, Desebbe O, Vincent JL, Sarah S, Rinehart J, Van Obbergh L, Hapfelmeier A, Saugel B. Monitoring of pulse pressure variation using a new smartphone application (Capstesia) versus stroke volume variation using an uncalibrated pulse wave analysis monitor: a clinical decision making study during major abdominal surgery. J Clin Monit Comput. 2019;33(5):787-93. https://doi.org/10.1007/s10877-018-00241-4.

23. Zlicar M, Novak-Jankovic V, Blagus R, Cecconi M. Predictive values of pulse pressure variation and stroke volume variation for fluid responsiveness in patients with pneumoperitoneum. J Clin Monit Comput. 2018;32(5):825-32. https://doi.org/10.1007/s1087 7-017-0081-4.

24. Landis JR, Koch GG. The measurement of observer agreement for categorical data. Biometrics. 1977;33(1):159-74.

25. Rogge DE, Nicklas JY, Haas SA, Reuter DA, Saugel B. Continuous noninvasive arterial pressure monitoring using the vascular unloading technique (CNAP system) in obese patients during laparoscopic bariatric operations. Anesth Analg. 2018;126(2):45463. https://doi.org/10.1213/ane.0000000000002660.

26. Benes J, Giglio M, Brienza N, Michard F. The effects of goaldirected fluid therapy based on dynamic parameters on postsurgical outcome: a meta-analysis of randomized controlled trials. Crit Care. 2014;18(5):584. https://doi.org/10.1186/s1305 4-014-0584-z.

27. Coeckelenbergh S, Delaporte A, Ghoundiwal D, Bidgoli J, Fils JF, Schmartz D, Van der Linden P. Pleth variability index versus pulse pressure variation for intraoperative goal-directed fluid therapy in patients undergoing low-to-moderate risk abdominal surgery: a randomized controlled trial. BMC Anesthesiol. 2019;19(1):34. https://doi.org/10.1186/s12871-019-0707-9.

28. Nguyen NT, Lee SL, Anderson JT, Palmer LS, Canet F, Wolfe BM. Evaluation of intra-abdominal pressure after laparoscopic and open gastric bypass. Obes Surg. 2001;11(1):40-5. https://doi. org/10.1381/096089201321454097.

29. Atkinson TM, Giraud GD, Togioka BM, Jones DB, Cigarroa JE. Cardiovascular and ventilatory consequences of laparoscopic surgery. Circulation. 2017;135(7):700-10. https://doi.org/10.1161/ CIRCULATIONAHA.116.023262.

30. Jacques D, Bendjelid K, Duperret S, Colling J, Piriou V, Viale JP. Pulse pressure variation and stroke volume variation during increased intra-abdominal pressure: an experimental study. Crit Care. 2011;15(1):R33. https://doi.org/10.1186/cc9980.

31. Renner J, Gruenewald M, Quaden R, Hanss R, Meybohm P, Steinfath M, Scholz J, Bein B. Influence of increased intra-abdominal pressure on fluid responsiveness predicted by pulse pressure variation and stroke volume variation in a porcine model. Crit Care Med. 2009;37(2):650-8. https://doi.org/10.1097/CCM.0b013e3181959864.

32. Bliacheriene F, Machado SB, Fonseca EB, Otsuke D, Auler JO Jr, Michard F. Pulse pressure variation as a tool to detect hypovolaemia during pneumoperitoneum. Acta Anaesthesiol Scand. 2007;51(9):1268-72. https://doi.org/10.111 1/j.1399-6576.2007.01432.x.

33. Rosendal C, Markin S, Hien MD, Motsch J, Roggenbach J. Cardiac and hemodynamic consequences during capnoperitoneum and steep Trendelenburg positioning: lessons learned from robot-assisted laparoscopic prostatectomy. J Clin Anesth. 2014;26(5):383-9. https://doi.org/10.1016/j.jclinane.2014.01.014.

34. Tapar H, Karaman S, Dogru S, Karaman T, Sahin A, Tapar GG, Altiparmak F, Suren M. The effect of patient positions on perfusion index. BMC Anesthesiol. 2018;18(1):111. https://doi. org/10.1186/s12871-018-0571-z.

Publisher's Note Springer Nature remains neutral with regard to jurisdictional claims in published maps and institutional affiliations. 